\title{
Selective one-pot two-step C-C bond formation using MOFs with mild basicity as heterogeneous catalysts
}

\author{
Francisco G. Cirujano, ${ }^{*} \dagger^{[\mathrm{a}]}$ Elena López-Maya, $\dagger^{[\mathrm{b}]}$ L. Marleny Rodríguez-Albelo, ${ }^{[\mathrm{b}]}$ Elisa Barea,${ }^{[\mathrm{b}]}$ Jorge \\ A.R. Navarro ${ }^{[b]}$ and Dirk E. De Vos ${ }^{[a]}$
}

\begin{abstract}
Copper ion exchanged nickel pyrazolate frameworks behave as selective heterogeneous catalysts for the one-pot twostep (Henry reaction/Michael type addition) synthesis of neuroactive pharmaceutical intermediates, starting from nitromethane and benzaldehyde. Tuning the basicity of multifunctional MOF catalysts through ion exchange with copper(II) cations allows to selectively direct the tandem $\mathrm{C}-\mathrm{C}$ bond forming process towards the desired pharmaceutical intermediate.
\end{abstract}

Serotonin reuptake inhibitors and GABA ( $\mathrm{\gamma}$-aminobutyric acid) receptor agonists have found potential pharmacological applications in the treatment of multiple neurological pathologies Different synthetic strategies and new homogeneous catalysts have been proposed in order to access this type of compounds. ${ }^{[1]}$ In particular, the use of multi-step cascade reactions reduces the number of synthetic steps and chemical waste. For example, simple components such as nitromethane, benzaldehyde, indole or dimethyl malonate produce compounds $\mathbf{1}, 2$ and $\mathbf{3}$ through a "one-pot" two-step reaction (Scheme 1). ${ }^{[2]}$ These molecules are intermediates in the synthesis of $\beta$-phenyl$\gamma$-aminobutyric acid (phenibut), tryptamine analogues or tetrahydro- $\beta$-carboline drugs.

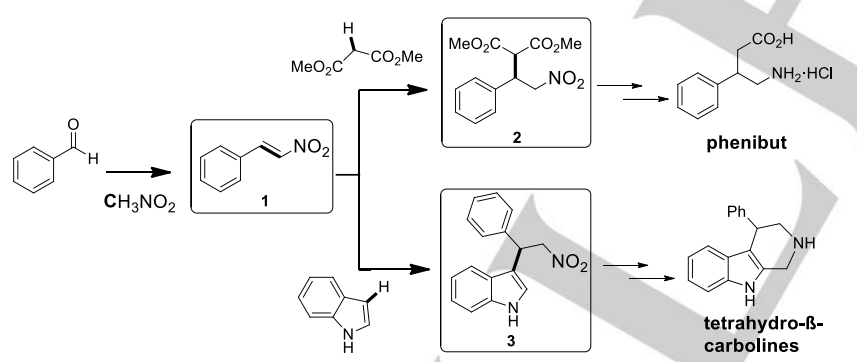

Scheme 1. Multi-step synthesis of neuroactive pharmaceutical intermediates starting from benzaldehyde, nitromethane, indole or dimethyl malonate precursors.

[a] Dr. F. G. Cirujano, Prof. D. E. De Vos

Centre for Surface Chemistry and Catalysis, Department of Microbial and Molecular Systems (M2S)

KU Leuven

Celestijnenlaan 200F, 3001 Leuven, Belgium

[b] Dr. E. López-Maya, Dr. M. Rodríguez-Albelo, Dr. E. Barea, Prof. J. A.R. Navarro

Departamento de Química Inorgánica

Universidad de Granada

Av. Fuentenueva S/N, 18071 Granada, Spain

†Author Contributions: These authors contributed equally to this work
The process starts with a nitroaldol condensation between benzaldehyde and nitromethane to form $\beta$-nitrostyrene 1 . Then the addition of dimethyl malonate or indole to the reaction mixture will produce the Michael adduct $\mathbf{2}$ or the indole derivative 3. Finally, the nitro groups can be further reduced to obtain the GABA and tryptamine scaffolds, respectively. The replacement of soluble catalysts ${ }^{[1 \mathrm{~b}-\mathrm{g}],[3]}$ by heterogeneous counterparts simplifies the removal of the catalyst from the reaction mixture and may allow to reuse it. ${ }^{[4]}$ Herein, a new family of post-synthetically modified metal-organic frameworks is employed to selectively direct the different C-C bond forming reactions towards the desired products 2 and $\mathbf{3}$ starting from benzaldehyde and nitromethane as starting materials.

Metal-organic frameworks (MOFs) are interesting heterogeneous catalysts because they contain a large amount of well-positioned metal sites (nodes) in a periodic porous framework constructed by multitopic organic molecules (linkers) ${ }^{[5]}$ In particular, our group have prepared the $\left[\mathrm{Ni}_{8}(\mathrm{OH})_{4}\left(\mathrm{H}_{2} \mathrm{O}\right)_{2}(\mathrm{BDP})_{6}\right]$ (NiBDP) metal-organic framework in sizeable amounts by reacting the relatively inexpensive $\mathrm{H}_{2} \mathrm{BDP}$ [1,4-bis(pyrazol-4-yl)benzene] linker with non-precious first-row nickel salts. The resulting MOF has a porous, non interpenetrated FCU crystalline framework, based on octanuclear nickel (II) clusters connected by BDP linkers, showing high thermal and chemical stability in basic media. ${ }^{[6]}$ We have also studied the formation of the linker defective $\mathrm{K}\left[\mathrm{Ni}_{8}(\mathrm{OH})_{6}\left(\mathrm{BDP} \mathbf{X}_{5.5}\right]\right.$ (NiBDP_X@K) MOF, where BDP_X= benzene-1,4-bispyrazolate-2-X; $\mathrm{X}=\mathrm{H}, \mathrm{OH}$, or $\mathrm{NH}_{2}$. The DFT (Density Functional Theory) energy-minimized structure of the $\mathrm{SBU}$, modelled as anionic $\left[\mathrm{Ni}_{8}(\mathrm{OH})_{6}(\text { pyrazolate })_{11}\right]^{-}$moieties, contains exposed hydroxides replacing the pyrazolate vacancies. It was proposed that the exposed hydroxides of the metal cluster and the polar functional groups of the organic linkers behave as active adsorption sites. Moreover, the presence of extraframework $\mathrm{K}^{+}$cations opens the way to ion exchange processes as recently demonstrated with $\mathrm{Ba}^{2+}$ ions, yielding defective ion exchanged materials. Both the extraframework cations and defects are responsible for the excellent $\mathrm{CO}_{2}, \mathrm{SO}_{2}$ adsorption and ion conductive properties of these multifunctional MOFs. ${ }^{[7]}$

In view of these results, we have now explored the impact of the post-synthetic modification of the NiBDP_X@K materials, by cation exchange with copper ions, on the catalytic properties. Exposure of NiBDP_X@K materials to a methanolic $0.1 \mathrm{M}$ $\mathrm{Cu}\left(\mathrm{ClO}_{4}\right)_{2}$ solution leads to new ion exchanged solids NiBDP@Cu, NiBDP_OH@Cu and NiBDP_NH $\mathbf{N H}_{2} @ \mathbf{C u}$. The nickel, copper and hydroxide ions of the inorganic clusters are bridged by 1,4-bis(pyrazol-4-yl)benzene linkers, which creates a site isolation in the nodes of the framework. This approach prevents the deactivation of incompatible active sites, such as copper or nickel Lewis acid centres and basic centres, by means of 

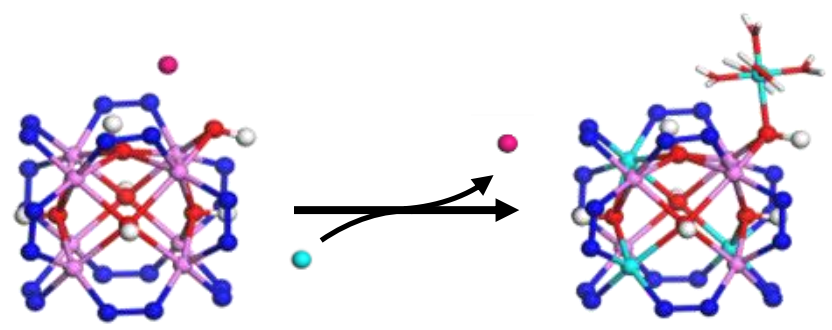

Figure 1. Schematic representation of the transformation of $\mathrm{K}\left[\mathrm{Ni}_{8}(\mathrm{OH})_{6}\left(\mathrm{BDP} \_\mathrm{X}\right)_{5.5}\right]$ by ion exchange with $\mathrm{Cu}\left(\mathrm{ClO}_{4}\right)_{2}$ to produce $\left[\mathrm{Cu}\left(\mathrm{H}_{2} \mathrm{O}\right)_{5}\right]_{0.5}\left[\mathrm{Ni}_{5} \mathrm{Cu}_{3}(\mathrm{OH})_{6}\left(\mathrm{BDP} \_\mathrm{X}\right)_{5.5}\right]$. For simplicity, only the secondary building unit is shown. Ni (pink); K (magenta); $\mathrm{Cu}$ (cyan); N (blue); O (red); $\mathrm{H}$ (white).

keeping them apart in the crystalline metal-organic framework support.

Inductively coupled plasma mass spectrometry analysis (ICPMS) is indicative of the ion exchange process in the NiBDP_OH@Cu and NiBDP_NH $\mathbf{N H}_{2} @ \mathbf{C u}$ materials together with some encapsulation of $\mathrm{Cu}\left(\mathrm{ClO}_{4}\right)_{2}$ ion pairs. Noteworthily, NiBDP@Cu contains a considerably higher copper concentration, indicative of a probable partial replacement of nickel ions in the octanuclear metal hydroxide cluster framework nodes. We have found that the $\mathrm{K}$ concentration diminishes by $90 \%$ in the NiBDP@Cu, showing that the exchange process is quite efficient (see Table S1 on page 6 of the supporting information). Furthermore, UV-Vis, Raman and XPS spectroscopies seems to indicate the presence of $\mathrm{Cu}$ (II) inside the metal clusters (see Figures S14, S17 and S18 in the supporting information).

Herein, we have used these MOFs as heterogeneous catalysts for the first step of Scheme 1. This consists in the Henry reaction between benzaldehyde and nitromethane followed by dehydration of the nitroaldol adduct to produce $\beta$-nitrostyrene 1. ${ }^{[8]}$ On the one hand, when using nitromethane as solvent, the selectivity to the desired product $\mathbf{1}$ is never higher than $70 \%$, due to the addition of a second molecule of nitromethane to $\beta$-nitrostyrene. ${ }^{[9]}$ As we will demonstrate below, the selectivity towards the desired nitroalkene versus the dinitroalkane can be used as a diagnostic tool to investigate the basic strength of these MOFs. On the other hand, the benzaldehyde conversion is very low in the presence of aprotic solvents, such as toluene ( $<40 \%$ after $72 \mathrm{~h}$ of reaction). In this sense, 2-butanol was selected as the optimal reaction solvent. The best selectivity to the desired Henry reaction product 1 was obtained with the unfunctionalized MOF catalysts (NiBDP, NiBDP@K and NiBDP@Cu). In this case, benzaldehyde reacts with nitromethane to produce the desired $\beta$-nitrostyrene 1 as the main product after $48 \mathrm{~h}$ (>90\% selectivity). For the $\mathrm{KOH}$ treated NiBDP@K catalyst, the benzaldehyde conversion further increase (56\% conversion) with respect to the pristine NiBDP material (39\% conversion). In fact, when the $\mathrm{pH}$ of an aqueous suspension of the MOFs (after $1 \mathrm{~h}$ of stirring at room temperature) is measured, ${ }^{[10]}$ there is an increase in $\mathrm{pH}$ on passing from NiBDP ( $\mathrm{pH}$ 7.8) to NiBDP@K (pH 8.3). This suggests the presence of basic sites in the $\mathrm{K}$ exchanged material, as reported also for hydrotalcites. ${ }^{[11]}$
When NiBDP@Cu is used as catalyst, $81 \%$ conversion of benzaldehyde and $94 \%$ selectivity to 1 are obtained after $48 \mathrm{~h}$, supporting the use of $\mathrm{Cu}$ as catalyst for the nitroaldol reaction. ${ }^{[12]}$ NiBDP@Cu clearly outperforms other copper MOFs such as CuBTC, which only converts $2 \%$ of aldehyde after $60 \mathrm{~h}$ of reaction with an excess of nitromethane at $100{ }^{\circ} \mathrm{C} .{ }^{[13]} \mathrm{A}$ hot filtration test confirms the heterogeneous nature of the catalytic process since the reaction stops completely after the removal of NiBDP@Cu from the liquid reaction medium (Fig. S20). The copper exchanged NiBDP@Cu gives rise to higher benzaldehyde conversion and selectivity to 1 than NiBDP and NiBDP@K. In general, all the NiBDP_X@Cu catalysts exhibit higher selectivity to product $\mathbf{1}$ with respect to the ones without $\mathrm{Cu}$ (see Figure 2).

The benzaldehyde conversion after 48 increase on passing from NiBDP (39\% conversion) to NiBDP_OH (81\% conversion) and NiBDP_ $\mathbf{N H}_{2}(93 \%$ conversion) functionalized materials. This indicates the higher activity of the hydrophilic $\mathrm{NH}_{2}$ and $\mathrm{OH}$ functionalized materials. Although the presence of such functional groups in the MOF have been proposed to activate acid hydrogens in $\mathrm{C}-\mathrm{C}$ forming reactions involving carbonyls and enolates, such as aldol condensations and additions, ${ }^{[5 f-k]}$ in our hands the use of the pure amino and hydroxyl functionalized linkers (BDP_ $\mathrm{NH}_{2}$ and BDP_OH) as catalysts does not enhance the conversion of benzaldehyde with respect to the blank reaction. One important observation for this acid-base catalysed process is that the selectivity towards the desired Henry product 1 (at the maximum benzaldehyde conversion after $48 \mathrm{~h}$ of reaction, see Figure S24) decreases as the basicity of the MOF increases, resulting in a mixture of nitro and dinitro products. This is related to the formation of the (1,3-dinitropropan-2yl)benzene $\mathbf{1 b}$, due to the Michael addition of a second molecule of nitromethane to the nitroalkene 1 . The further consumption of the intermediate $\mathbf{1}$ towards $\mathbf{1 b}$, is favoured in the presence of the amino $\left(\mathrm{NH}_{2}\right)$ and hydroxyl $(\mathrm{OH})$ functionalized solids. ${ }^{[9],[14]}$

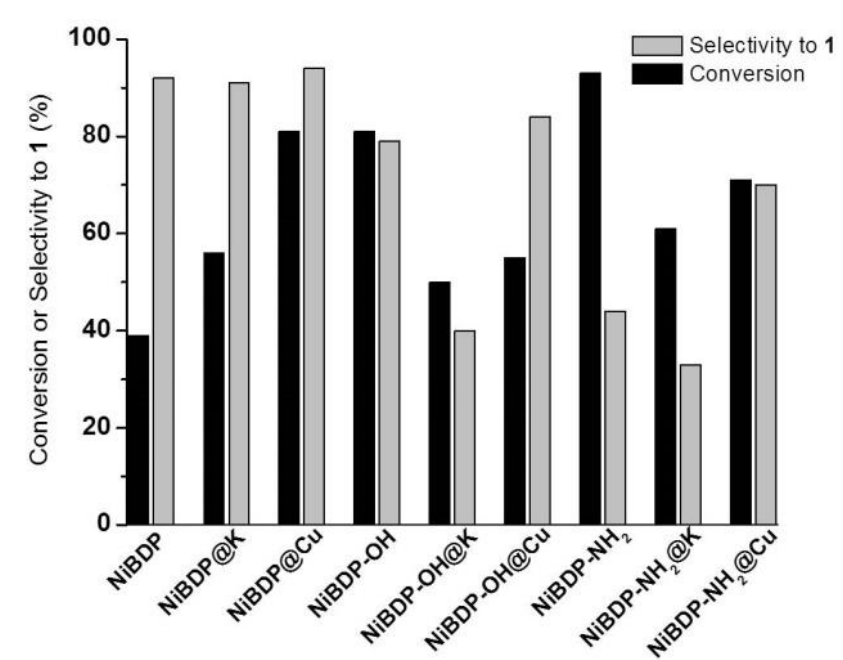

Figure 2. Benzaldehyde conversion, selectivity to product 1 (after $48 \mathrm{~h}$ of reaction) for the Henry reaction between $0.1 \mathrm{mmol}$ of benzaldehyde and $1 \mathrm{mmol}$ of nitromethane, using $10 \mathrm{mg}$ of MOF. 


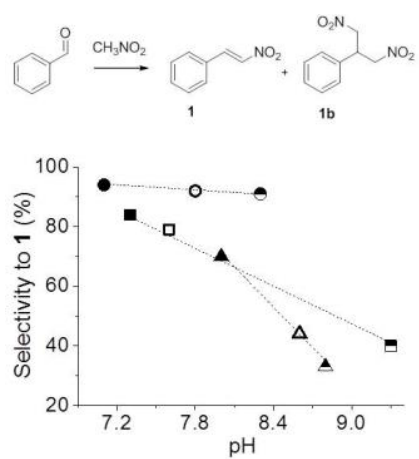

(a)

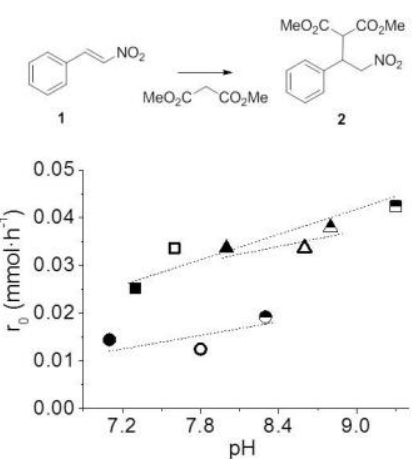

(b)
Figure 3. Effect of basicity ( $\mathrm{pH}$ of a suspension of $4 \mathrm{mg}$ of MOF in $10 \mathrm{ml}$ of water stirring for $1 \mathrm{~h}$ ) of the NiBDP_X@M materials, where $\mathbf{X}=\mathrm{H}$ (circle), $\mathrm{OH}$ (square), $\mathrm{NH}_{2}$ (triangle), $\mathrm{M}=$ no exchanged metal (empty circle), $\mathrm{K}$ (half empty), $\mathrm{Cu}$ (full), on the catalytic activity of Michael type additions. Both the addition of nitromethane (a) or dimethyl malonate (b) to $\mathbf{1}$, increases with the basicity of the MOF. Dashed line serves as a guide to the eye.

Thus, although the benzaldehyde conversions and reaction rates are higher in the case of the functionalized materials, the further consumption of $\mathbf{1}$ to form $\mathbf{1 b}$ decreases the selectivity to the desired product 1 (see Figure 3a). The higher selectivity to 1 when using the $\mathrm{Cu}$ exchanged materials may be attributed to the lower basicity of the $\mathrm{Cu}$ exchanged MOFs. In contrast with the polar $\mathrm{NH}_{2} / \mathrm{OH}$ groups, the presence of (Lewis acid) copper sites in the MOF seems to decrease the basicity of the material.

The catalytic performance of the solid MOFs for this first reaction step was compared with that of the homogeneous metal precursors of the MOF, i.e. nickel acetate $\left[\mathrm{Ni}(\mathrm{OAc})_{2}\right]$ and copper perchlorate $\left[\mathrm{Cu}\left(\mathrm{ClO}_{4}\right)_{2}\right]$ (see Table S2). On the one hand, when $\mathrm{Ni}(\mathrm{OAc})_{2}$ is used as catalyst, slightly higher yields of 1 are obtained with respect to NiBDP after $48 \mathrm{~h}$ $(48 \%$ vs $36 \%){ }^{[15]}$ However, the TOF (turnover frequency) values for both NiBDP and $\mathrm{Ni}(\mathrm{OAc})_{2}$ are similar $\left(\sim 0.04 \mathrm{~h}^{-1}\right)$. On the other hand, the $\mathrm{Cu}\left(\mathrm{ClO}_{4}\right)_{2}$ salt produces only moderate yields of product $1(27 \%)$, in contrast to other copper Lewis acid catalysts in the presence of $\mathrm{N}$-containing ligands. ${ }^{[12]}$ This seems to indicate that the encapsulated ion pairs that may remain after the washing treatments do not significatly contribute to the catalytic activity of the MOF. Noteworthily, when $\mathrm{Cu}\left(\mathrm{ClO}_{4}\right)_{2}$ is used in combination with $\mathrm{Ni}(\mathrm{OAc})_{2} \cdot \mathrm{H}_{2} \mathrm{O}$, the TOF value $\left(0.02 \mathrm{~h}^{-1}\right)$ decreases with respect to that obtained using NiBDP@Cu $\left(0.08 \mathrm{~h}^{-1}\right)$.

Furthermore, we aimed to proceed with a second reaction step by adding dimethyl malonate or indole to the reactor after the Henry reaction (see Scheme 1) in one pot. Since NiBDP@Cu does not readily induce further reaction of intermediate $\mathbf{1}$ with nitromethane, this catalyst can be employed to further convert $\mathbf{1}$ into pharmaceutical intermediates $\mathbf{2}$ and $\mathbf{3}$, in a second step. Regarding the synthesis of $\mathbf{2}$, when dimethyl malonate is added to the $\beta$-nitrostyrene 1 formed during the first step in the presence of the NiBDP@Cu as heterogeneous catalyst, the Michael adduct $\mathbf{2}$ is quantitatively obtained (full conversion of $\mathbf{1}$ and $100 \%$ selectivity to 2 ) after $12 \mathrm{~h}$. On the contrary, only $29 \%$ and $64 \%$ of pure $\beta$-nitrostyrene 1 are converted to 2 for the blank and NiBDP, respectively. Unfortunately, in contrast to the high selectivity to 1 obtained with NiBDP@Cu, it is not possible to obtain high yields of $\mathbf{2}$ in "one-pot" way using the polar $\mathrm{NH}_{2}$ or $\mathrm{OH}$ functionalized materials due to the low $\beta$ nitrostyrene 1 yield obtained in the Henry reaction $(50 \%$ and $64 \%$ yield, respectively).

In order to compare all the MOFs already studied in the first reaction step in the Michael addition reaction $(1 \rightarrow 2)$, we performed the addition of dimethyl malonate to pure $\beta$ nitrostyrene 1 employing another vessel than the one used for the Henry reaction. The TOF values obtained were higher for the $\mathrm{NH}_{2}$ and $\mathrm{OH}$ functionalized solids $\left(0.8 \mathrm{~h}^{-1}\right)$ than for the $\operatorname{NiBDP}\left(0.3 \mathrm{~h}^{-1}\right)$, as was observed for the Henry reaction. The parallel trend between $\mathrm{pH}$ of the MOF suspension and catalytic activity is particularly clear for this reaction (see Figure $3 \mathrm{~b}$ ), with the $\mathrm{K}$ exchanged materials as the most basic and active ones. Interestingly, the basicity of the suspensions increases with the diminution of the particle size NiBDP_X@Cu MOF particles (see Figures S8S10) which should be related to exposed hydroxides on the external surface of the particles. For instance, the small size $(<1 \mu \mathrm{m})$ of $\mathbf{N i B D P} \mathbf{N H}_{2} @ \mathbf{C u}$ gives rise to basic suspensions $(\mathrm{pH} \sim 8)$ showing a relatively high TOF value $\left(0.8 \mathrm{~h}^{-1}\right)$ for the Michael addition of dimethyl malonate to pure 1 compound.

To prove the feasibility of the tandem process for the production of substituted indoles, a stoichiometric amount of indole was added to the reaction mixture after $48 \mathrm{~h}$ of Henry reaction. The $\beta$-nitrostyrene 1 formed during the first Henry reaction step was quantitatively converted (in one pot) after 12 additional hours to the 3-(2-nitro-1phenylethyl)-1H-indole 3 in the presence of the NiBDP@Cu MOF catalyst (full conversion of $\mathbf{1}$ and $100 \%$ selectivity to 3). It is important to highlight that none of the homogeneous catalysts $\mathrm{Ni}(\mathrm{OAc})_{2}, \mathrm{KOH}$ or $\mathrm{Cu}\left(\mathrm{ClO}_{4}\right)_{2}$ converted more than $40 \%$ of 1 to 3 after $12 \mathrm{~h}$ (starting from pure $\beta$-nitrostyrene 1 in a different pot, but under the same reaction conditions). The catalytic activity of the MOFs for this reaction $(\mathbf{1} \rightarrow \mathbf{3})$ shows no direct correlation with their basicity $(\mathrm{pH}$ of the suspension), although the NiBDP material and the homogeneous $\mathrm{Ni}(\mathrm{OAc})_{2}$ have lower activity than the rest of exchanged $(\mathrm{Cu}, \mathrm{K})$ or functionalized $\left(\mathrm{NH}_{2}, \mathrm{OH}\right)$ materials (Table S2 and Figure S28). At present we do not have a complete explanation for the high activity of $\mathrm{NH}_{2} / \mathrm{OH}$ functionalized MOFs (NiBDP_NH $\mathbf{N}_{2}, \mathbf{N i B D P} \mathbf{O H}$ ) compared to the NiBDP. One hypothesis may be the hydrogen bonding activation of $\beta$-nitrostyrene by the hydrophilic $\mathrm{NH}_{2}$ or $\mathrm{OH}$ functional groups in the linker, as recently described for 1,3-disiloxanediols. ${ }^{16}$

Moreover, the copper ions introduced into the defective NiBDP@K increase the catalytic activity of NiBDP@Cu for this reaction (see Figure S28), which has been proven to be 
Table 1. TOFs $\left(10^{-2} \cdot \mathrm{h}^{-1}\right)$ for the individual steps $\left(1^{\text {st }}\right.$ : benzaldehyde to $\mathbf{1}$; $2^{\text {nd }}: \mathbf{1}$ to 3$)^{\text {a }}$ and yields of 3 after $60 \mathrm{~h}$ of one-pot two-step process (benzaldehyde to 3 ) using different MOF catalysts.

\begin{tabular}{|c|c|c|c|c|}
\hline & Catalyst & $\begin{array}{l}\text { TOF }_{1 \text { st Step }} \\
\left(10^{-2} \cdot \mathrm{h}^{-1}\right)\end{array}$ & $\begin{array}{l}\text { TOF }_{2 \text { nd Step }} \\
\left(10^{-2} \cdot \mathrm{h}^{-1}\right)\end{array}$ & $\begin{array}{l}\text { Yield of } 3 \\
\text { One-pot (\%) }\end{array}$ \\
\hline 1 & NiBDP@Cu & 8 & 120 & 70 \\
\hline 2 & NiBDP@K & 5 & 100 & 49 \\
\hline 3 & NiBDP & 4 & 40 & 22 \\
\hline 4 & $\mathrm{Ni}(\mathrm{pz})_{2}$ & 5 & 41 & 39 \\
\hline 5 & $\mathrm{Ni}(\mathrm{OH})_{2}$ & 1 & 16 & 21 \\
\hline 6 & $\mathrm{Ni}_{2}$ (dhtp) & 1 & 15 & 2 \\
\hline 7 & $\mathrm{Cu}(\mathrm{pz})_{2}$ & 2 & 64 & 13 \\
\hline 8 & $\mathrm{Cu}(\mathrm{OH})_{2}$ & 1 & 13 & 22 \\
\hline 9 & $\mathrm{Cu}_{3}(\mathrm{btc})_{2}$ & 1 & 14 & 3 \\
\hline
\end{tabular}

${ }^{\mathrm{a}} \mathrm{mmol}$ of $\mathbf{1}$ or $\mathbf{3}$ obtained per $\mathrm{mmol}$ of $\mathrm{Cu}$ and/or $\mathrm{Ni}$ and time (for conversions $<30 \%$ ). Conditions: $0.1 \mathrm{mmol}$ of substrate (benzaldehyde or 1), $10 \mathrm{mg}$ of catalyst, $0.5 \mathrm{ml}$ 2-butanol, $100^{\circ} \mathrm{C}$. Pyrazole ( $\left.\mathrm{Hpz}\right)$; benzene1,4-dicarboxylic-2,5-dihydroxy acid $\left(\mathrm{H}_{4} \mathrm{dhtp}\right)$; benzene-1,3,5-tricarboxylic acid $\left(\mathrm{H}_{3} \mathrm{btc}\right)$

catalysed by MOFs with Lewis acid sites. ${ }^{17}$ However, in contrast with the better performance of $\mathrm{Cu}_{3}(\mathrm{btc})_{2}$ in toluene than in 2-butanol, for NiBDP@Cu the reaction is favoured in the alcohol solvent. Again, this is probably due to the hydrogen bonding activation of the nitro group of $\beta$-nitrostyrene by the 2 -butanol solvent at $100^{\circ} \mathrm{C}$, producing around $30 \%$ yield of 3 after $12 \mathrm{~h}$ in the absence of a catalyst. In contrast, when the reaction is performed in toluene in the absence of a catalyst, no trace of $\mathbf{3}$ was detected after $12 \mathrm{~h}$.

The catalytic results for the one-pot synthesis of the substituted indole 3 have been compared with those obtained using different nickel or copper containing solids (see Table 1). In our hands, the NiBDP@Cu outperforms the nickel and copper MOFs (entries 6 and 9) as well as the pyrazolates (entries 4 and 7 ) and hydroxides (entries 5 and 8) catalysts tested. The performance of the basic nickel pyrazolate $\mathrm{Ni}(\mathbf{p z})_{2}$ (entry 4 ) for the one-pot, two-step process is better than that of the copper analogue (entry 7). An excess of basic sites favours the generation of byproducts, such as the further reaction of $\mathbf{1}$ to $\mathbf{1 b}$, which occurs in the case of solids with high basicity such as the NiBDP@K (entry 2) or $\mathrm{Ni}(\mathrm{OH})_{2}$ (entry 5). The copper pyrazolate $\mathbf{C u}(\mathbf{p z})_{2}$ shows high activity for the 2nd step, which is in line with the performance of NiBDP@Cu for this particular reaction. For all NiBDP materials, the crystalline structure and surface area were maintained after the first and second step of the tandem process, with only a slight decrease for NiBDP@Cu. A tentative reaction mechanism of the tandem process using this type of MOF is shown in Figure 4.

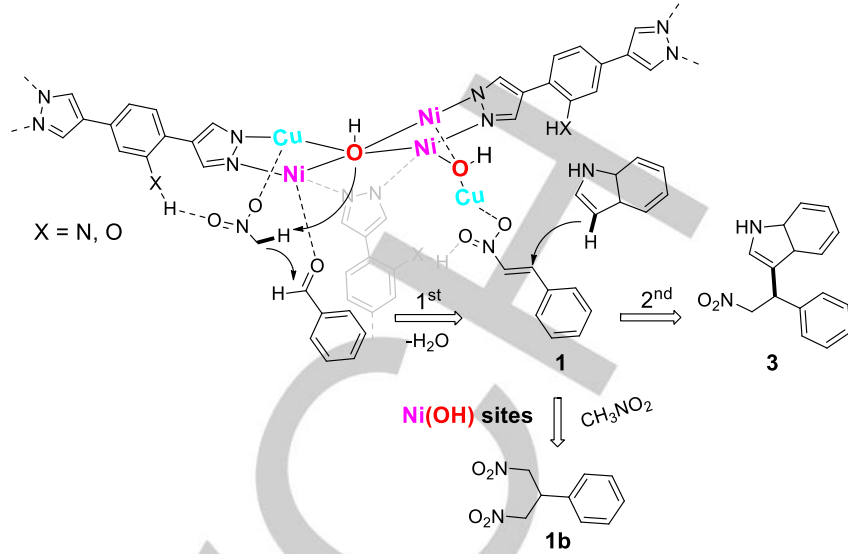

Figure 4. Schematic representation of the binuclear bridged cluster (some linkers have been intentionally omitted for clarity) where either nickel, copper and basic sites copperatively activate both carbonyl group of the benzaldehyde, the nitro group of the nitromethane and $\beta$-nitrostyrene molecules.

In conclusion, the NiBDP_X@Cu MOFs presents a higher selectivity to compound $\mathbf{1}$, due to its milder basicity, than both NiBDP_X@K and NiBDP_X parent solids, with a higher activity for Michael type additions. The best results in terms of activity and selectivity are obtained for NiBDP@Cu due to the simultaneous presence of copper (II) ions at the nickel-oxo clusters and the adequate basicity to avoid consecutive Michael addition of a second molecule of nitromethane to intermediate $\mathbf{1}$. This allows for the coupling of a second $\mathrm{C}-\mathrm{C}$ bond forming reaction step with the aim to obtain important pharmaceutical precursors (2 and 3 ) from simple molecules. The novel NiBDP@Cu material described here allows the optimal performance of the onepot Henry reaction/Michael type addition as a high yield $(70 \%)$ tandem process, directing the benzaldehyde starting product towards pharmaceutical intermediates 2 and $\mathbf{3}$. This work shows the potential catalytic application of nickel pyrazolate type highly porous and stable MOFs as basic catalysts for multi $\mathrm{C}-\mathrm{C}$ bond forming reactions, presenting higher activities than copper or nickel carboxylate, pyrazolate and hydroxide solids. Future efforts in the synthesis, characterization and new catalytic applications of these materials are expected, with a particular interest in the characterization of the copper sites in the crystal structure.

\section{Experimental Section}

The synthesis of MOFs samples NiBDP, NiBDP-OH and NiBDP- $\mathbf{N H}_{2}$ were prepared according to the procedure reported by our group. ${ }^{[6]}$ NiBDP_X@K MOFs were prepared by suspending $0.055 \mathrm{mmol}$ NiBDP_X in $0.35 \mathrm{M} \mathrm{KOH}$ absolute ethanol solution $(5.5 \mathrm{~mL})$ and stirred overnight. NiBDP_X@Cu were prepared prepared suspending 100mg of NiBDP $\mathbf{X} @ \mathrm{~K}$ in $12 \mathrm{~mL}$ of $0.1 \mathrm{M}$ methanolic solution of $\mathrm{Cu}\left(\mathrm{ClO}_{4}\right)_{2}$ and stirring for $16 \mathrm{~h}$ at room temperature. Catalytic tests were performed 
stirring $1 \mathrm{mmol}$ of the substrate(s) (10eq of nitromethane for the Henry reaction) and $10 \mathrm{mg}$ of MOF catalyst in a round bottom flask under reflux of 2-butanol $(0.5 \mathrm{ml})$. The consumption of the starting material was monitored by GC-FID using decane as internal standard. The reaction products were characterized by NMR and MS (see supporting information)

\section{Acknowledgements}

Spanish MINECO (CTQ2014-53486-R), EU Feder funding, Flemish government (Methusalem CASAS2), FWO, Belspo (IAP-PAI 7/05) and Marie-Curie Individual Fellowship (MSCA-IF 750391-SINMOF) program are acknowledged for financial support.

Keywords: Heterogeneous catalysis - Tandem reaction - C-C bond formation $\cdot$ Defective MOF $\cdot$ Tuneable basicity

[1] (a) B. Lopez-Iglesias, C. Perez, J. Morales-Garcia, S. Alonso-Gil, A Perez-Castillo, A. Romero, M. G. Lopez, M. Villarroya, S. Conde, M. I. Rodriguez-Franco, J. Med. Chem. 2014, 57, 3773-3785; (b) A. A. Sukhanovaa, Y. V. Nelyubinab, S. G. Zlotin, Mendeleev Commun. 2016 26, 471-473; (c) E. Veverková, S. Bilka, R. Baran, R. Šebesta, Synthesis 2016, 48, 1474-1482; (d) I. J. Montoya-Balbás, B. ValentínGuevara, E. López-Mendoza, I. Linzaga-Elizalde, M. Ordoñez, P Román-Bravo, Molecules 2015, 20, 22028-22043; (e) D. Almasi, D. A Alonso, E. Gomez-Bengoa, C. Najera, J. Org. Chem. 2009, 74, 61636168; (f) R. P. Herrera, V. Sgarzani, L. Bernardi, A. Ricci, Angew. Chemie Int. Ed. 2005, 44, 6576-6579; (g) G. Huang, H. Sun, X. Quu, Y Shen, J. Jiang, L. Wang, J. Organometallic Chem. 2011, 696, 2949 2955. (h) A. E. Laine, C. Lood, A. M. P. Koskinen, Molecules 2014, 19, 1544-1567.

[2] (a) B. M. Trost, V. S. C. Yeh, H. Ito, N. Bremeyer, Org. Lett. 2002, 4, 2621-2623; (b) M. J. Climent, A. Corma, S. Iborra, ChemSusChem 2009, 2, 500-506; (c) F. G. Cirujano, A. Leyva-Perez, A. Corma, F. X. Llabrés i Xamena, ChemCatChem 2013, 5, 538-549; (d) A. LeyvaPerez, P. García-García, A. Corma, Angew. Chemie Int. Ed. 2014, 53, 8687-8690, (e) A. Dhakshinamoorthy, H. Garcia, ChemSusChem 2014 7, 2392-2410; (f) F. Zhang, H. Jiang, X. Wu, Z. Mao, H. Li, ACS Appl. Mater. Interfaces 2015, 7, 1669-1677; (g) T. Tsubogo, H. Oyamada, S. Kobayashi, Nature 2015, 520, 329-332; (h) H. Ishitani, Y. Saito, T. Tsubogo and S. Kobayashi, Org. Lett. 2016, 18, 1346-1349.

[3] (a) K. D. Hargrave, C. K. Miao, WO9806719; (b) K. I. Chung, J. E. Lee, WO2004046081; (c) A. G. Thakur, M. P. Kulkarni, WO2013103967.

[4] (a) C. P. Fei, T. H. Chan, Synthesis 1982; 6 467-468; (b) P. Laszlo, M. T. Montaufier, S. L. Randriamahefa, Tetrahedron Lett. 1990, 31, 4867 4874; (c) A. Corma, R. M. Martín-Aranda, F. Sánchez, J. Catal. 1990 126, 192-198; (d) M. J. Climent, A. Corma, S. Iborra, A. Velty, J. Mol. Catal. A 2002, 182-183, 327-342; (e) K. Akutu, H. Kabashima, T. Seki, H Hattori, Appl. Catal. A 2003, 247, 65-74; (f) D.J. Macquarrie, R Maggi, A. Mazzacani, G. Sartori, R. Sartorio, Appl. Catal. A 2003, 246 183-188; (g) A. Corma, H. García, Adv. Synth. Catal. 2006, 348, 13911412; (h) S. Shylesh, A. Wagener, A. Seifert, S. Ernst, W. R. Thiel, Angew. Chem. Int. Ed. 2010, 49, 184-187; (i) E. Gianotti, U. Diaz, A Velty, A. Corma, Catal. Sci. Technol. 2013, 3, 2677-2688; (j) U. Díaz, D. Brunel, A. Corma, Chem Soc Rev., 2013, 42, 4083-4097; (k) N. A Brunelli, C. W. Jones, J. Catal. 2013, 308, 60-72; (I) P. J. Waller, F. Gándara, O. M. Yaghi, Acc. Chem. Res. 2015, 48, 3053-3063 (m) U Díaz, A. Corma, Coord. Chem. Rev. 2016, 311, 85-124; (n) H.-S. Xu,
S.-Y. Ding, W.-K. An, H. Wu, W. Wang, J. Am. Chem. Soc. 2016, 138, 11489-11492.

[5] (a) P. Valvekens, F. Vermoortele, D. De Vos, Catal. Sci. Technol. 2013 3, 1435-1445; (b) A. Dhakshinamoorthy, M. Opanasenko, J. Cejka and H. Garcia, Catal. Sci. Technol. 2013, 3, 2509-2540; (c) P. GarciaGarcia, M. Muller, A. Corma, Chem. Sci. 2014, 5, 2979-3007; (d) J. Jiang, O. M. Yaghi, Chem. Rev. 2015, 115, 6966-6997; (e) J. Canivet, M. Vandichel, D. Farrusseng, Dalton Trans. 2016, 45, 4090 4099; (f) J. Gascon, U. Aktay, M.D. Hernandez-Alonso, G.P.M. van Klink, F. Kapteijn, J. Catal. 2009, 261, 75-87; (g) F. Vermoortele, R Ameloot, A. Vimont, C. Serre, D. De Vos, Chem. Commun. 2011, 47, 1521-1523; (h) F. X. Llabres i Xamena, F. G. Cirujano, A. Corma Microporous Mesoporous Mater. 2012, 157, 112-117; (i) M. Položij, E. Pérez-Mayoral, J. Čejka, J. Hermann, P. Nachtigall, Catal. Today 2013 204, 101-107. (j) P. Valvekens, M. Vandichel, M. Waroquier, V. Van Speybroeck, D. De Vos, J. Catal., 2014, 317, 1-10; (k) J. Hajek, M. Vandichel, B. Van de Voorde, B. Bueken, D. De Vos, M. Waroquier, V. Van Speybroeck, J. Catal. 2015, 331, 1-12; (I) P. Valvekens, M. Stalpaert, G. De Winter, D. De Vos, Top. Catal. 2016, 59, 17571764; (m) X. Wang, S. Zhao, Y. Zhang, Z. Wang, J. Feng, S. Song, H. Zhang, Chem. Sci. 2016, 7, 1109-1114; (n) S.-N. Zhao, X.-Z. Song, S.Y. Song, Hong-jie Zhang, Coord. Chem. Rev. 2017, 337, 80-96.

[6] N. M. Padial, E. Quartapelle Procopio, C. Montoro, E. López, J. E. Oltra, V. Colombo, A. Maspero, N. Masciocchi, S. Galli, I. Senkovska, S. Kaskel, E. Barea, J. A. R. Navarro, Angew. Chemie Int. Ed. 2013, 52, 8290-8294.

[7] (a) E. López-Maya, C. Montoro, V. Colombo, E. Barea, J. A. R. Navarro, Adv. Funct. Mater. 2014, 24, 6130-6135; (b) C. Montoro, P. Ocõn, F. Zamora, J. A R. Navarro, Chem. Eur. J. 2016, 22, 1646-1651; (c) L. M. Rodríguez-Albelo, E. López-Maya, S. Hamad, R. Ruiz-Salvador, S. Calero, J. A. R. Navarro, Nat. Commun. 2017, 8, 14457.

[8] R. H. Wollenberg, S. J. Miller, Tetrahedron Lett. 1978, 35, 3219-3304

[9] K. Motokura, M. Tada, Y. Iwasawa, Angew. Chemie Int. Ed. 2008, 47, 9230-9235.

[10] A. Herbst, A. Khutia, C. Janiak, Inorg. Chem. 2014, 53, 7319-7333.

[11] B. M. Choudary, M. Lakshmi Kantam, Ch. Venkat Reddy, K. Koteswara Rao, F. Figueras, Green Chem. 1999, 1, 187-189.

[12] (a) Y. Xiong, F. Wang, X. Huang, Y. Wen, X. Feng, Chem. Eur. J. 2007 13, 829-833; (b) K. Ma, J. You, Chem. Eur. J. 2007, 13, 1863-1871; (c) S. Jammi, M. A. Ali, S. Sakthivel, L. Rout, T. Punniyamurthy, Chem Asian J. 2009, 4, 314-320; (d) G. Murugavel, P. Sadhu, T. Punniyamurthy, Chem. Rec. 2016, 16, 1906-1917; (e) A. Tăbăcaru, N. Xhaferaj, L. M. D. R. S. Martins, E. C. B. A. Alegria, R. S. Chay, C. Giacobbe, K. V. Domasevitch, A. J. L. Pombeiro, S. Galli, C. Pettinari, Inorg. Chem. 2016, 55, 5804-5817; (f) E. A. Tarasenko, I. P. Beletskaya Synthesis 2017, 49, 1689-1701.

[13] S. A. Sotnik, K. S. Gavrilenko, A. S. Lytvynenko, S. V. Kolotilov, Inorg Chim. Acta 2015, 426, 119-125.

[14] S. L. Poe, M. Kobaslija, D. T. McQuade, J. Am. Chem. Soc. 2006, 128 15586-15587.

[15] (a) A. P. C. Ribeiro, Y. Y. Karabach, L. M. D. R. S. Martins, A. G Mahmoud, M. F. C. Guedes da Silva, A. J. L. Pombeiro, RSC Adv 2016, 6, 29159-29163; (b) M. Sharma, B. Das, G. V. Karunakar, L. Satyanarayana, K. K. Bania, J. Phys. Chem. C 2016, 120, 13563 13573.

[16] K. M. Diemoz, J. E. Hein, S. O. Wilson, J. C. Fettinger, A. K. Franz, J. Org. Chem 2017, DOI: 10.1021/acs.joc.7b00875.

[17] (a) L. Mitchell, B. Gonzalez-Santiago, J. P. S. Mowat, M. E. Gunn, P. Williamson, N. Acerbi, M. L. Clarke, P. A. Wright, Catal. Sci. Technol. 2013, 3, 606-617; (b) L. Mitchell, P. Williamson, B. Ehrlichová, A. E. Anderson, V. R. Seymour, S. E. Ashbrook, N. Acerbi, L. M. Daniels, R. I. Walton, M. L. Clarke, P. A. Wright, Chem. Eur. J. 2014, 20, 17185 17197; (c) A. Nagaraj, D. Amarajothi, J. Colloid Interface Sci. 2017, 494, 282-289. 
Entry for the Table of Contents (Please choose one layout)

Layout 1:

\section{COMMUNICATION}

Copper exchanged MOFs show tuneable basicity, activity and selectivity in C-C bond forming reactions

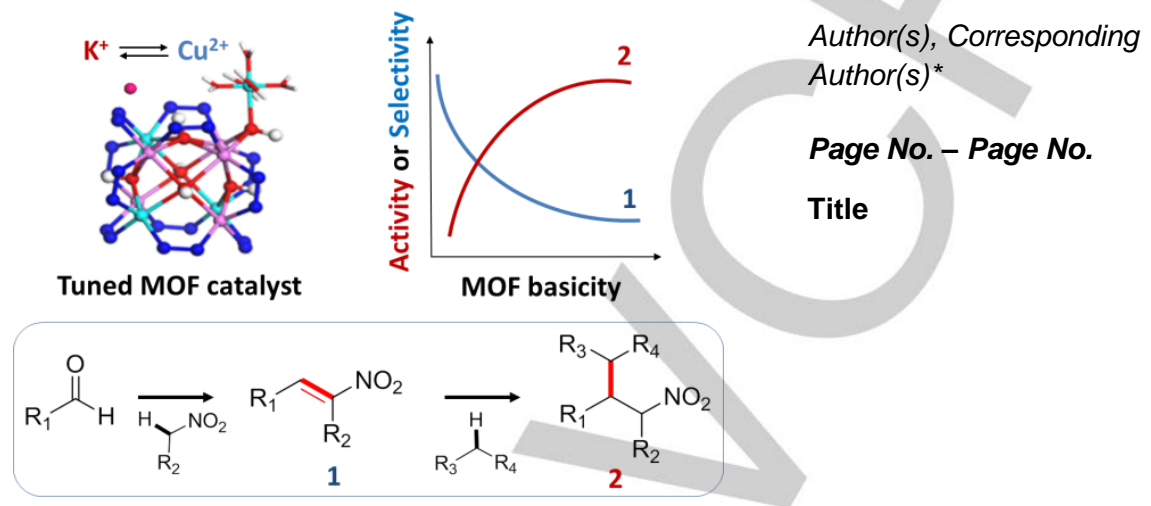

